\title{
EFFECTS OF CHLORALOSE ANESTHESIA ON SPINAL REFLEXES
}

\author{
Muneo Shimamura, Toshio Yamauchi AND Mamoru AoKI \\ Department of Physiology, Hokkaido University \\ School of Medicine, Sapporo, Japan
}

From the original work of HANRIOT and RICHET, 18939), it has been known that animals anesthetized with chloralose exhibit a generalized jerky muscular reaction. Various stimuli, including tactile, sound, photic, etc., yielded a late reflex response in spinal motor nerves, which effected jerky muscular contractions $^{1)}$. Some parts of the reflex mechanism of the late response may be the same as those of the spino-bulbo-spinal (SBS) reflex mechanism ${ }^{15}$. The SBS reflex may involve polysynaptic reflex pathways in the spinal cord and brainstem $^{14)}$. This SBS reflex was obtained in a larger response, while a spinal segmental polysynaptic reflex response was reduced by chloralose anesthesia. The reduction of a segmental polysynaptic reflex may be due to the depressing action of the chloralose on the transmission process of polysynaptic reflex pathways ${ }^{15)}$.

HaAse and Meulen, $1961^{8)}$, have demonstrated that chloralose has a depressing action on the Renshaw cell recurrent inhibition. Contrarily, there is an augmentation and prolongation of the presynaptic inhibition in primary afferent fibers from muscles ${ }^{6}$. Therefore, in the present experiments, an attempt has been made to analyze more precisely the effects of chloralose anesthesia on various spinal reflexes, to obtain evidence of the depressing effects of chloralose on spinal interneurons, and to extend knowledge of the mechanisms effecting the chloralose jerky muscular contraction.

\section{METHODS}

Experiments were performed on twenty-five adult cats. A spinal transection was made at the $C_{1}$ level through the atlanto-occipital membrane under ether anesthesia. The animals were then maintained under artificial respiration. A laminectomy at the lumbosacral region was also performed. When immobilization was necessary, gallamine triethiodide (Flaxedil) was administered intravenously until all muscular movements ceased,

Electrical stimuli were applied, with bipolar silver electrodes, to spinal dorsal roots

Received for publication November 15, 1967.

島村宗夫, 山内俊雄, 青木 藩 
and nerves; to muscles and cutis, with electronic stimulators, from which rectangular pulses of $0.3 \mathrm{msec}$ duration were delivered through isolation transformers and they were repeated at a rate of one per two seconds. Reflex responses were recorded by bipolar silver wire electrodes from the ventral root $\mathrm{L}_{7}$ (or $\mathrm{S}_{1}$ ) and dorsal root $\mathrm{L}_{7}$ (or $\mathrm{S}_{1}$ ). The pia-arachnoid was removed over each region to be penetrated by the microelectrode. The microelectrode was of the glass capillary type filled with $3 \mathrm{M} \mathrm{KCl}$ or $2 \mathrm{M} \mathrm{NaCl}$ and with resistances ranging from 10 to 20 megohms. Potentials from the cord dorsum were recorded with a silver ball-tipped electrode. A silver-silver chloride plate attached to the lumbar muscles acted as the indifferent electrode for the potential recordings. To obtain the antidromic volley of the dorsal root, a stimulating microelectrode was placed among the terminals of afferent fibers from the dorsal root in the cord, as described by WALL, 195816). Observations were made with a double beam oscilloscopic recording system, set at a time constant of $0.1 \mathrm{sec}$, unless otherwise noted. Photographs of a parallel enclosed "slave" oscilloscope were made on film.

The alpha-chloralose (Kuhlman, Paris) was administered intravenously, usually $25 \mathrm{mg} / \mathrm{kg}$ initially, followed in some cases by additional doses of $10 \mathrm{mg} / \mathrm{kg}$. This stage of anesthesia permitted examination of reflexly evoked generalized motor reactions in intact spinal and brain animals ${ }^{15}$. Blood pressure and heart rate were checked from the carotid arteria on several spinal cats, as to whether any changes are produced by chloralose administration.

Observations were started about 2-3 hours after cessation of the ether anesthesia. Exposed nerves and the spinal cord were bathed in warm mineral oil, and the temperature of the oil pool was maintained at about $37^{\circ} \mathrm{C}$ with an infrared lamp.

\section{RESULTS}

Chloralose anesthetized spinal cats did not exhibit generalized jerky muscular reactions, even when a large dosage of $100 \mathrm{mg} / \mathrm{kg}$ was administered. Blood pressure and heart rate also were not changed markedly by chloralose anesthesia until dosage levels of about $45 \mathrm{mg} / \mathrm{kg}$. However, at large dosage level of $80-100 \mathrm{mg} / \mathrm{kg}$, blood pressure and heart rate were decreased markedly. In this series of experiments, therefore, chloralose was administered at dosage levels of lower than $45 \mathrm{mg} / \mathrm{kg}$.

1. Effects of chloralose on spinal mono- and poly-synaptic reflexes. In spinal cats, reflex responses were recorded from the ventral root $L_{7}$ (or $S_{1}$ ) following stimulation of the sural nerve, nerves to gastrocnemius-soleus and tibialis anticus muscles, independently. The stimulation of the nerve to the gastrocnemius muscle yielded the well-known mono- and poly-synaptic reflex responses (MSR, PSR) from the ventral root $\mathrm{L}_{7}$. If chloralose $(25-35 \mathrm{mg} / \mathrm{kg})$ was given intravenously, the MSR was increased slightly in amplitude, while the PSR was reduced in degree. The similar augmentation of the MSR and the reduction of the PSR were also observed in succeeding cases, even after all the ventral roots and dorsal roots from $L_{4}$ to $S_{2}$ were transected. In this series of experiments, of course, a stimulus was applied to the dorsal root $\mathrm{L}_{7}$, and the response was recorded from the ventral root $\mathrm{L}_{7}$; in another case, reflex 


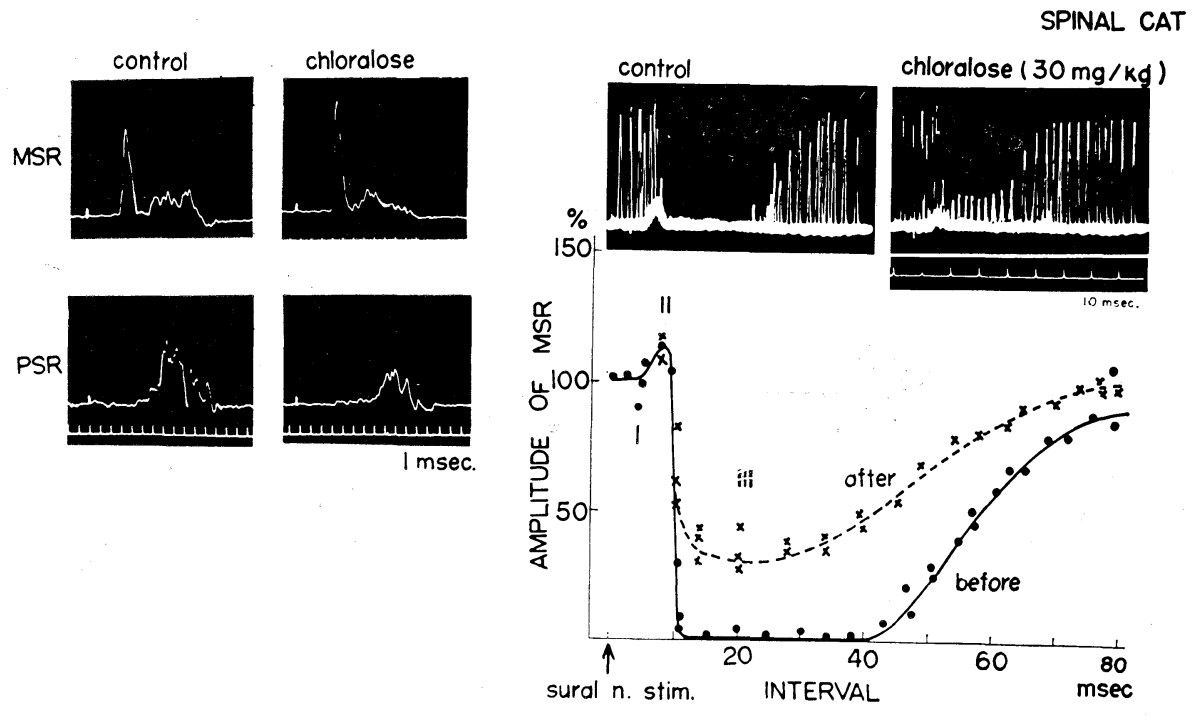

FIG. 1. Effects of chloralose anesthesia on monosynaptic and polysynaptic reflex in a spinal cat. Left pictures: Comparison between before and after chloralose anesthesia $(30 \mathrm{mg} / \mathrm{kg}$ i. v.) on mono- and poly-synaptic reflex responses recorded from $\mathrm{VRL}_{7}$ following stimulation of the nerve to the gastrocnemius muscle (upper records) and on polysynaptic reflex response recorded from the $\mathrm{VRL}_{7}$ induced by sural nerve stimulation (lower records). Right graph: Amplitude variations of monosynaptic reflex response to gastrocnemius nerve stimulation relative to control $=100 \%$, plotted against intervals, when conditioned by single sural nerve stimulation at increasing intervals, before (solid line) and after (dotted line) chloralose administration. Photogramms show superimposed pictures of MSR following sural nerve conditioning stimulation.

responses were recorded from the ventral root, following stimulation of the nerve to the tibialis anticus muscle and of the sural nerve (FIG. 1).

Intracellular potentials were recorded in 15 extensor motoneurons innervating the gastrocnemius-soleus muscle and 12 flexor motoneurons innervating the tibialis anticus muscle with a glass capillary microelectrode. However, they did not show any significant differences in membrane potentials and spike potentials with chloralose administration.

2. Effects of chloralose on inhibitory influences of the sural nerve to the extensor monosynaptic reflex responses. A conditioning shock was applied to the ipsilateral sural nerve, this shock evoked a segmental PSR in the $\mathrm{VRL}_{7}$. The local extensor MSR in the $\mathrm{VRL}_{7}$, following stimulation of the nerve to the gastrocnemius-soleus muscle, was utilized as a test response. When the interval between the conditioning and testing shocks was increased gradually, the test MSR, in almost every case, showed an initial slight decrease in amplitude for a short interval (I), followed by a slight increase in amplitude for a short 
period (II). A second marked decrease in amplitude of about $20 \mathrm{msec}$ duration was observed (III). When chloralose $(15-35 \mathrm{mg} / \mathrm{kg})$ was administered to the cat, such a response pattern of the extensor MSR was modified as follows; the second phase of the diminution (III) was slightly decreased in degree; however, an initial diminution (I) and an initial enhancement (II) were not altered by chloralose administration (FIG. 1, right pictures).

When a conditioning shock was applied to the contralateral sural nerve, the test MSR was changed as follows; if the interval between the conditioning and testing stimuli was about $7 \mathrm{msec}$, the test MSR became strikingly reduced in amplitude. This diminution lasted up to about $35 \mathrm{msec}$. If chloralose (15$35 \mathrm{mg} / \mathrm{kg}$ ) was administered intravenously, such a diminution pattern was reduced slightly in degree.

3. Effects of chloralose on the Renshaw cell recurrent inhibition. HAASE and MEULEN $^{8)}$ have demonstrated clearly the depressing effect of chloralose on the Renshaw cell recurrent inhibition. The present series of experiments confirms their findings. Unitary discharges induced by repetitive stimulation of the dorsal root were recorded from a spinal ventral rootlet of $\mathrm{L}_{7}$. When repetitive

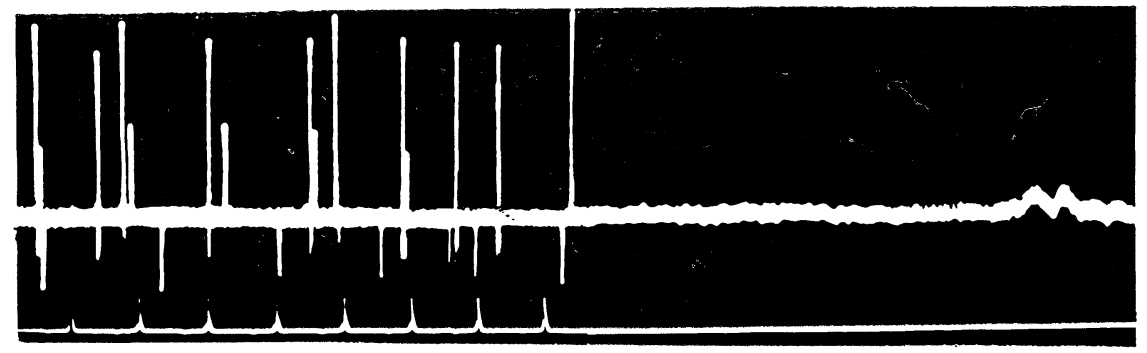

chloralose ( $30 \mathrm{mg} / \mathrm{kg}$ )

stim. to VRL7

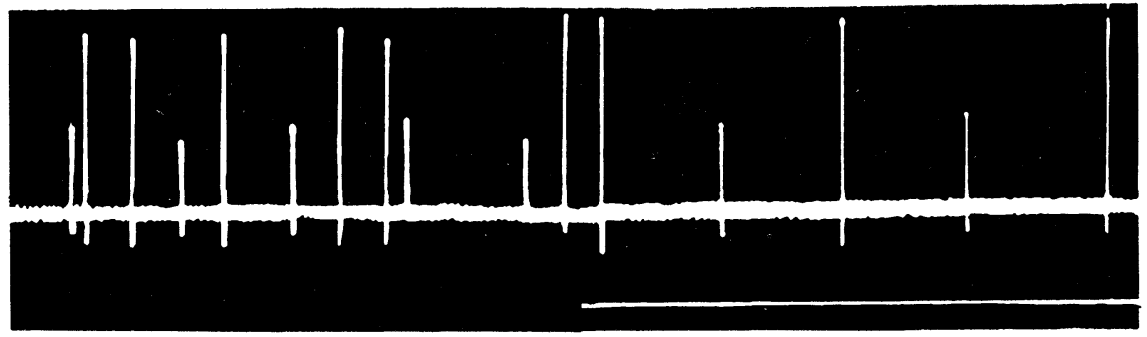

stim. to VRL7

FIG. 2. Effects of chloralose anesthesia on the Renshaw cell recurrent inhibition. In a spinal cat, unitary discharges were recorded from the ventral rootlet of $\mathrm{L}_{7}$ following repetitive stimuli to the $\mathrm{L}_{7}$ dorsal root. Depression of these discharges were observed following repetitive stimulation of the other part of the ventral root $\mathrm{L}_{7}$. This depression was reduced by chloralose administration ( $30 \mathrm{mg} / \mathrm{kg}$, i. v. lower record). Time scale is in $100 \mathrm{msec}$ intervals. 
stimuli were applied to the other part of the ventral root of $\mathrm{L}_{7}$ antidromically, these unitary discharges were reduced in frequency or abolished (FIG. 2 upper picture). This depression of reflex responses may be caused by the Renshaw cell recurrent inhibitory mechanisms ${ }^{12)}$. When chloralose was administered, the depression of reflex discharges was reduced (FIG. 2 lower picture).

4. Effects of chloralose on the spinal cord dorsum potentials induced by the sural nerve stimulation. A single shock to the sural nerve yielded two negative and one positive potentials from the dorsal surface of the spinal cord at the lumbosacral segment. These were designated $\mathrm{N}_{1}, \mathrm{~N}_{2}$ and $\mathrm{P}$ potentials, respectively ${ }^{2}$.

If chloralose $(15-40 \mathrm{mg} / \mathrm{kg})$ was administered, both negative $\left(\mathrm{N}_{2}\right)$ and positive potentials were reduced slightly in amplitude, while the $\mathrm{N}_{1}$ potential was not altered (FIG. 3 left pictures).

\section{SPINAL CAT \\ CHLORALOSE ( $25 \mathrm{mg} / \mathrm{kg}$ )}
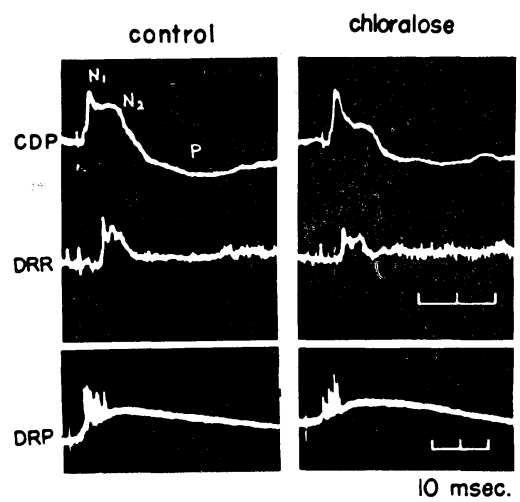

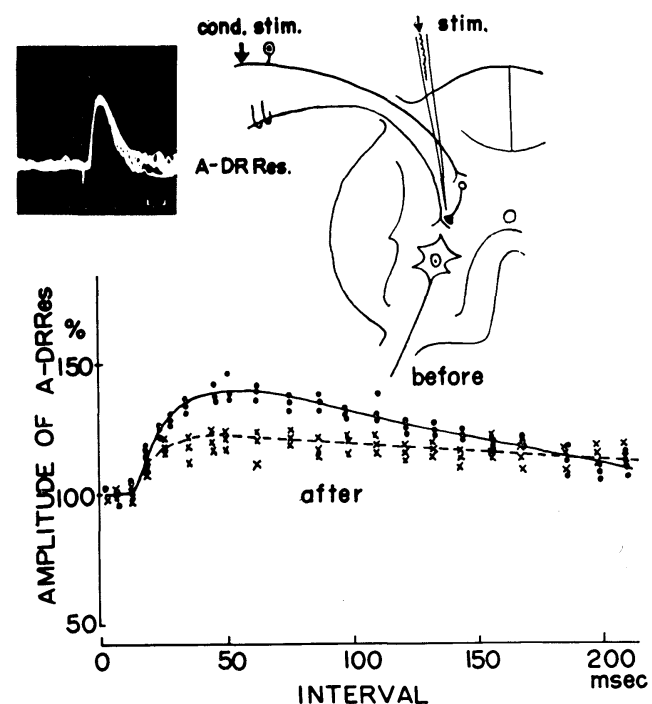

FIG. 3. Effects of chloralose anesthesia on cord dorsum potentials (CDP), dorsal root potentials (DRP) and dorsal root reflex (DRR), they were recorded from $\mathrm{L}_{7}$ segment following stimulation of the sural nerve. Right: Amplitude variations of the antidromic dorsal root response induced by stimulation among the terminals of afferent fibers from the gastrocnemius muscle, which plotted against intervals, when conditioned by single sural nerve stimulation at increasing intervals, before (solid line) and after (dotted line) chloralose administration (25 mg/kg i. v.). Photogram shows superimposed records of the antidromic dorsal root response (A-DRRes).

5. Effects of chloralose on the dorsal root potential (DRP) and dorsal root reflex $(D R R)$ at the $L_{7}$, induced by the sural nerve stimulation. A single shock to the sural nerve yielded the dorsal root potential (DRP), recorded by a DC amplifier at the point of entry from the dorsal root at the $\mathrm{L}_{7}$ segment. Dorsal 
root reflexes (DRR) were occasionally superimposed on the potential. When chloralose $(25-35 \mathrm{mg} / \mathrm{kg})$ was administered, both the DRP and DRR were reduced in amplitude slightly. These potentials were never augmented in spinal cats.

A second set of observations were designed to analyse membrane potential changes in the group Ia fibers by means of the intracellular microelectrode technique. In three spinal cats, 15 group Ia fibers of the gastrocnemius muscle were selected on the basis of the results of the conduction velocity and an appearance of the "pause" during the muscle twitch. Stimulation of the sural nerve yielded a depolarization in the group Ia fibers. This began with a delay of about $4 \mathrm{msec}$, corresponding in time to the local segmental polysynaptic reflex response from the ventral root, and endured over $200 \mathrm{msec}$.

When chloralose was administered intravenously, the depolarization of the group Ia fibers was slightly reduced in amplitude and was slightly prolonged in duration.

6. Effects of chloralose on an augmentation of antidromic potentials in the primary afferent fibers following sural nerve stimulation. WALL, $1958^{16)}$, demonstrated an alternative method of detecting depolarization of primary afferent fibers by testing their excitability to brief current pulses applied through a coarse extracellular microelectrode. A stimulating microelectrode was placed among the terminals of afferent fibers from the gastrocnemius muscle in the cord. Antidromic volleys were recorded from the peripheral nerve of the gastrocnemius muscle as a test. When the conditioning shock was applied to the ipsilateral sural nerve, and the interval between conditioning and testing shocks was increased gradually, the test antidromic volley was increased in amplitude during long intervals (FIG. 3 right pictures). The time course of the increase in amplitude of the response in the nerve to the gastrocnemius muscle exactly matched the time course of the dorsal root potential of the group Ia fibers (FIG. 3 left pictures). The latency of the enhancement was about $4 \mathrm{msec}$. The total duration was in excess of $200-300 \mathrm{msec}$. If chloralose $(25-35 \mathrm{mg} / \mathrm{kg})$ was administered, the enhancement was slightly decreased.

7. Effects of chloralose on interlimb reflexes, between forelimb and hindlimb. LLOYD, $1942^{10)}$, showed that the brachial plexus stimulation yielded a reflex response, "the interlimb reflex" from the hindlimb motor nerve bilaterally. In the present series of experiments, the interlimb reflexes were utilized as an indication of the effects of chloralose. When a single shock was applied to the superficial branch of the radial nerve, a reflex response was observed in the ventral root $\mathrm{L}_{7}$ or in the motor nerves to the gastrocnemius and tibialis anticus muscles. Latency of the VR response was $11-13 \mathrm{msec}$ (FIG. 4). If chloralose $(20-35 \mathrm{mg} / \mathrm{kg})$ was administered, such a reflex response was reduced 


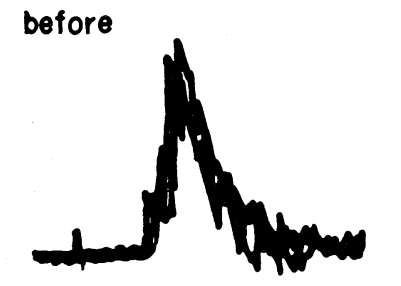

after Chloralose $25 \mathrm{mg} / \mathrm{kg}$
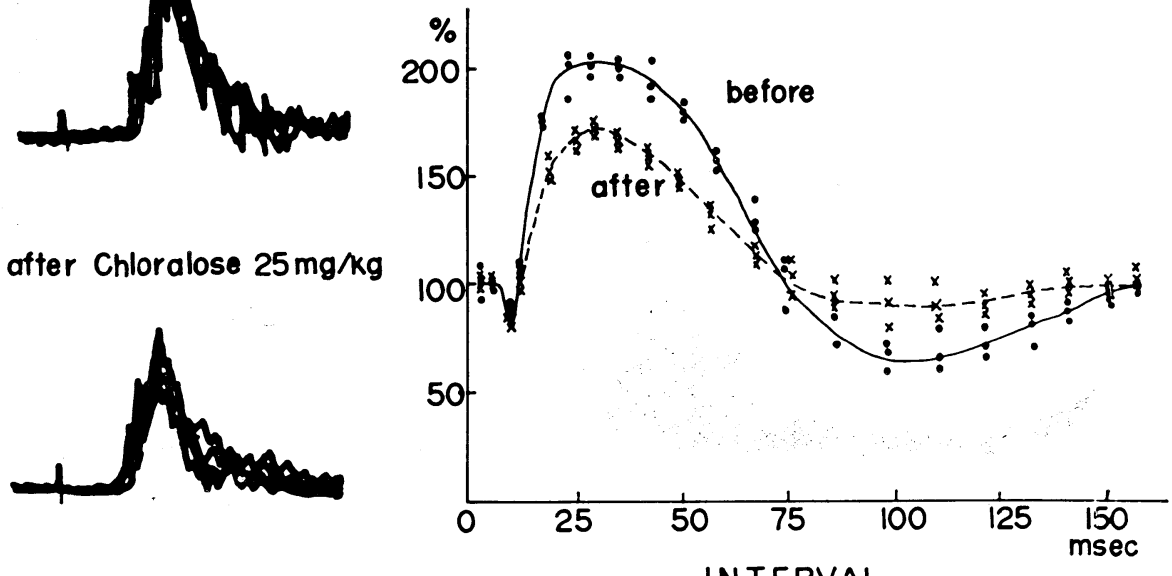

INTERVAL

FIG. 4. Effects of chloralose anesthesia on the interlimb reflexes. Left: Reflex response was recorded from the ventral root $\mathrm{L}_{7}$ following single shock to the superficial branch of the radial nerve in a spinal cat, before and after administration of the chloralose $(25 \mathrm{mg} / \mathrm{kg})$. Right: Amplitude variations of monosynaptic reflex response to gastrocnemius nerve stimulation plotted against intervals, when conditioned by single stimulation to the superficial branch of the radial nerve at increasing intervals, before (solid line) and after (dotted line) chloralose administration.

slightly in amplitude.

When a conditioning shock was applied to the superficial branch of the radial nerve, the test local MSR in lumbosacral segment showed an initial slight decrease in amplitude (I), followed by a marked increasing phase of MSR for about $25 \mathrm{msec}$ in duration (II). This was followed by, in some cases, an additional delayed decreasing phase of MSR in excess of $150 \mathrm{msec}$. If chloralose was administered, such an enhancement (II) and delayed diminution were slightly decreased, while the initial diminution (I) was not altered by chloralose anesthesia (FIG. 4 right pictures).

\section{DISCUSSION}

1. Effects of chloralose on the spinal polysynaptic reflexes. The present experiments indicate that the chloralose may have a depressing action on the spinal polysynaptic reflexes, which may be either on the synaptic transmission processes and/or the interneurons. These effects may not be obtained by changes in blood supplies, judging from the results of measurements of blood pressure and heart rate. These effects will be assumed on individual reflexes as follows : 
A) Segmental polysynaptic reflexes. The segmental polysynaptic reflex response of muscular and cutaneous origin was reduced in amplitude following administration of chloralose. This implies that chloralose may depress the synaptic transmission process in the spinal polysynaptic reflex pathway, and that interneurons and motoneurons may be involved. Pathways in the inhibitory process from cutaneous afferents to the extensor monosynaptic reflex response may also involve interneurons. This inhibitory action was also reduced by chloralose anesthesia, while the monosynaptic reflex response was increased in amplitude. These observations suggest that chloralose anesthesia may suppress interneurons, but may not depress motoneurons directly.

B) Renshaw cell recurrent inhibitory pathway. HAASE and MEULEN ${ }^{8)}$ showed that chloralose anesthesia reduced the inhibition from the Renshaw cells to the motoneurons. Our experiments confirm their observations.

C) Presynaptic inhibitory pathway of primary afferents. Dorsal root potentials may be related to the interneurons " D" (ECCLES et al., 19604,5,13)), and dorsal root reflexes may also involve interneurons (BROoKs et al., 1956 $6^{3)}$ ). These potentials were reduced by chloralose anesthesia. This implies that the potential reduction could be explained by the depressing effect of chloralose on these interneurons or the transmission process. ECCLEs et al., 1962 ${ }^{6}$, has shown that chloralose anesthesia augmented and prolonged dorsal root potentials. However, in their experiments, they used decerebrated cats, not spinal animals.

D) Descending interlimb reflex pathway. Stimulation of the nerve in the forelimb yielded an interlimb reflex response from the motor nerves in the hindlimb. This may involve polysynaptic reflex pathways ${ }^{7,10,11}$. A diminution (I) following enhancement (II) of the local lumbosacral monosynaptic reflex induced by stimulation of the forelimb afferent nerves was observed. The enhancement (II) may be related to polysynaptic reflex pathways, while the initial diminution (I) may be elicited by the monosynaptic reflex process as a direct inhibitory mechanisms ${ }^{10)}$. Chloralose anesthesia reduced the interlimb reflex response and enhancement (II). In contrast, an initial diminution (I) was not altered by chloralose anesthesia. These results may suggest a depression of interneurons by chloralose.

The observations suggest that the chloralose may have a depressing effect on the synaptic transmission and/or spinal interneurons which involve the underlying polysynaptic reflex mechanisms in the spinal cord. In the present experiments, there was no direct evidence of the depressing effect on interneurons. Intracellular recordings of 35 interneurons in three cats were examined. However, it was difficult to obtain direct evidence for these results.

2. Mechanisms of enhancement of the monosynaptic reflex induced by chloralose anesthesia. Chloralose anesthesia enhance slightly the monosynaptic reflex response, which may be explained by the following mechanisms: 1) Reduction 
of inhibitory action of the Renshaw cell recurrent mechanisms. 2) Reduction of inhibitory mechanisms from cutaneous afferents to the motoneurons. 3) Reduction of presynaptic inhibitory mechanisms in the muscular primary afferents fibers. 4) An enhancement of the transmission of the monosynaptic pathway. However, in the present series of experiments it could not be identified clearly whether one or all of the processes concern augmentation of the monosynaptic reflex response. In the present experiments, there was no direct evidence for change in membrane potentials in motoneurons.

Neural mechanisms of the appearance of the chloralose jerky muscular contraction may be due to the polysynaptic reflex pathways involving the supraspinal structures ${ }^{15)}$. However, in the present experiments, chloralose has a depressing effect on the spinal polysynaptic reflexes. Therefore, the development of chloralose jerky muscular contractions could not be explained by mechanisms in the spinal cord.

\section{SUMMARY}

1. Experiments were carried out on 25 adult cats under spinal transection at the $C_{1}$ level in order to extend observations on the chloralose jerky muscular contraction and to analyze the effects of chloralose on spinal reflexes.

2. Chloralose $(25-35 \mathrm{mg} / \mathrm{kg})$ was administered intravenously to spinal cats. These cats did not exhibit generalized jerky muscular reactions, even when a large dosage of $100 \mathrm{mg} / \mathrm{kg}$ was administered. Blood pressure and heart rate were not changed by chloralose anesthesia at a dosage level lower than $45 \mathrm{mg}$ / $\mathrm{kg}$. The following results were observed: 1) Slight augmentation of the monosynaptic reflex response, with a reduction in amplitude of polysynaptic reflex responses. 2) Reduction of the inhibitory influence of the sural nerve on the extensor monosynaptic reflex response. 3) Reduction of the Renshaw cell recurrent inhibition to the motoneurons. 4) Reduction of potential from the cord dorsum ( $\mathrm{N}_{2}$ and $\mathrm{P}$ ), dorsal root, and dorsal root reflex responses. 5) Reduction of augmentation of antidromic potentials of the primary afferent fibers following sural nerve stimulation. 6) Reduction of the interlimb reflex response and augmentation of the local lumbosacral monosynaptic reflex response to the forelimb nerve stimulation, without alteration of the initial diminution.

3. The observations suggest that the chloralose has a depressing action on the spinal polysynaptic reflex process and/or interneurons. Neural mechanisms of the chloralose jerky muscular contraction could not be due to mechanisms in the spinal cord.

The authors wish to express their thanks to Prof. B. FUJIMORI for his reading the manuscript. 


\section{REFERENCES}

1) Alvord, E.C., JR. And Fuortes, M. G.F. A comparison of generalized reflex myoclonic reactions elicitable in cats under chloralose anesthesia and under strychnine. Am. J. Physiol., 176: 253-261, 1954.

2) Bernhard, C. G. The spinal cord potentials in leads from the cord dorsum in relation to peripheral source of afferent stimulation. Acta Physiol. Scand., 19 Suppl., $106: 1-29,1953$.

3) Brooks, C. C. And Koizumi, K. Origin of the dorsal root reflex. J. Neurophysiol., $19: 61-74,1956$.

4) Eccles, J.C. Spinal neurones: Synaptic connexions in relation to chemical transmitters and pharmacological responses. Proc. I Int. Pharmac. Meet., 8: 157-182, ed. by B. Unvas. Oxford: Pergamon Press, 1962.

5) Eccles, J.C. The physiology of synapses. Berlin: Springer-Verlag, 1964.

6) Eccles, J.C., Kostyuk, P.G. And Schmidt, R.F. Central pathways responsible for depolarization of primary afferent fibers. J. Physiol., Lond., 161: 237-257, 1962.

7) Gernandt, B.E. and Megirian, D. Ascending propriospinal mechanisms. $J$. Neurophysiol., 24 : 364-376, 1961.

8) Haase, J. And von der Meulen, J.P. Die spezifische Wirkung der Chloralose auf die recurrent Inhibition tonischer Motoneurone. Pfiügers Arch. ges. Physiol., $274: 272-280,1961$.

9) Hanriot, M. and Richet, C. De l'action physiologique du chloralose. C. R. Seanc. Soc. Biol., 5 : 1-7, 129-133, 1893.

10) Lloyd, D. P.C. Mediation of descending long spinal reflex activity. J. Neurophysiol., 5 : 435-458, 1942.

11) Lloyd, D. P.C. And McIntyre, A. L. Analysis of forelimb hindlimb reflex activity in acutely decapitate cats. J. Neurophysiol., 11: 455-470, 1948.

12) Renshaw, B. Influence of the discharge of motoneurons upon excitation of neighboring motoneurons. J. Neurophysiol., 4 : 167-183, 1941.

13) Schmidt, R.F. Pharmacological studies on the primary afferent depolarization of the toad spinal cord. Pfiügers Arch. ges. Physiol., 277: 325-346, 1963.

14) Shimamura, M. And Livingston, R. B. Longitudinal conduction systems serving spinal and brain-stem coordination. J. Neurophysiol., 26: 258-272, 1963.

15) Shimamura, M. And Yamauchi, T. Neural mechanisms of "chloralose jerk" with special reference to its relationship with the spino-bulbo-spinal reflex. Jap. J. Physiol., 17 : 738-745, 1967.

16) WALL, P.D. Excitability changes in afferent fiber transmissions and their relation to slow potentials. J. Physiol., Lond. 142: 1-21, 1958. 